\title{
Especialização e vantagens competitivas do estado de Mato Grosso no mercado internacional: um estudo de indicadores de comércio exterior no período 1996-2007
}

\author{
Benedito Dias Pereira ${ }^{1}$ \\ Paula Luciana Silva ${ }^{2}$ \\ Alexandre Magno de Melo Faria ${ }^{3}$ \\ Gerson Rodrigues Silva ${ }^{4}$ \\ Lázaro Camilo Recompensa Joseph ${ }^{5}$
}

\begin{abstract}
Resumo: Identificam-se os grupos de produtos do Estado de Mato Grosso que exibem vantagens competitivas no comércio exterior durante o período 1996-2007. Para tanto, estimam-se indicadores de comércio exterior, tais como Vantagens Comparativas Reveladas, Índice de Contribuição ao Saldo da Balança Comercial e Taxa de Cobertura. Além disso, identificam-se pontos fortes e pontos fracos desse comércio. Os resultados apontam que o Estado possui vantagens competitivas em diversos produtos e é dependente da importação de outros. Esses caracteres moldam uma economia primário-exportadora, competitiva e com inserção externa bem-definida.
\end{abstract}

Palavras-chave: Competitividade; vantagem comparativa relevada; inserção externa.

\footnotetext{
${ }^{1}$ Doutor em Economia Agrícola pelo PIMES/UFPE. Professor do Curso de Ciências Econômicas e Coordenador do Mestrado em Agronegócios e Desenvolvimento da Faculdade de Economia da UFMT. E-mail: bdp@terra. com.br.

${ }^{2}$ Economista pela UFMT. Mestranda em Agronegócios e Desenvolvimento pela Faculdade de Economia da UFMT. E-mail: paula_luciana@hotmail.com.

${ }^{3}$ Doutor em Desenvolvimento Sócio-ambiental pelo NAEA/UFPA. Professor do Curso de Ciências Econômicas e do Mestrado em Agronegócios e Desenvolvimento da Faculdade de Economia da UFMT. E-mail: melofaria@ hotmail.com.

${ }^{4}$ Mestre em Economia Agrícola pela UFV. Professor do Curso de Ciências Econômicas da Faculdade de Economia da UFMT. E-mail: grsilva@ufmt.br.

${ }^{5}$ Doutor em Economia pela UNICAMP. Professor do Curso de Ciências Econômicas e do Mestrado em Agronegócios e Desenvolvimento da Faculdade de Economia da UFMT. E-mail: camilojoseph@hotmail.com.
} 


\title{
Specialization and competitive advantages of Mato Grosso state on the international market: $a$ study offoreign trade indicators on 1996-2007
}

\begin{abstract}
Are the identification of products groups of Mato Grosso State displaying competitive advantages in foreign trade during the period 1996-2007. Thus, are estimated some foreign trade indicators, such as Revealed Comparative Advantages, Index of Contribution to the Balance of Trade Balance and Rate of Coverage. Furthermore, it identifies strengths and weaknesses of that trade. The results show that the state has several competitive advantages in products and is dependent on the import of others. These characters shape a primary-exporting economy, competitive and with external insertion well-defined.
\end{abstract}

Keywords: Competitiveness; revealed comparative advantage; external insertion.

JEL: $F 59$

\section{Introdução}

A partir da última década do Século XX verificam-se transformações marcantes na nova ordem mundial, com a formação de grandes blocos políticoeconômicos, resultantes do processo de internacionalização do capital. Esse fato favoreceu o aprofundamento de novo padrão tecnológico, afetando heterogeneamente os Países considerados avançados, assim como os periféricos. Nesse contexto, ao se conhecer o setor exportador de uma unidade federativa, sua estrutura e especialidades, identificando, ademais, os produtos que exibem vantagens competitivas e que mais contribuem para o comércio exterior do País, aprimoram-se as condições para a formulação de políticas conducentes à adequada inserção internacional dessa unidade.

No período 1996-2007, o saldo da balança comercial do Brasil saltou de um déficit de US \$ 5,6 bilhões, para um superávit de US\$ 40,03 bilhões. Esse fenômeno pode ser explicado pelos efeitos da desvalorização cambial em 1999 e pelo inexpressivo crescimento do Produto Interno Bruto (PIB) do País durante esses anos, conforme ratifica Vicente (2005: 05):

Logo após o Plano Real, a balança comercial brasileira - superavitária entre 
1981 e 1994 - passou a apresentar déficits em conseqüência da sobrevalorização cambial. Com a adoção do câmbio flexível, em 1999, esses déficits diminuíram continuamente, e a partir de 2001 a balança comercial passou a apresentar superávits crescentes. Além dos efeitos do câmbio, a queda nas importações reflete as modestas taxas de crescimento que o País vem experimentando nos últimos anos.

O mesmo autor aponta que essa inversão do sinal do saldo da balança comercial é fruto majoritariamente da contribuição do agronegócio, em especial, dos produtos manufaturados e semi-manufaturados, que, segundo ele, chegou a responder por $54 \%$ do valor das exportações brasileiras em 2003. O atual estágio de desenvolvimento do agronegócio brasileiro, que coloca o País entre as nações mais competitivas do mundo na produção de commodities agroindustriais teve o seu momento de inflexão a partir de 2000, segundo Jank et al. (2005), em decorrência da desvalorização do real e do aumento da demanda no mercado internacional. De 2000 a 2006 , a produção nacional de grãos passou de 57,8 para 126 milhões de quilos e as exportações: de R $\$$ 18,1 bilhões para $\mathrm{R} \$ 46,2$ bilhões, exibindo, nesse caso, taxa de crescimento anual de $19,7 \%$.

Com referência aos novos padrões de competitividade, explicados principalmente pela abertura comercial, a estimativa de indicadores das diversas mercadorias ou agrupamento de mercadorias viabiliza análise mais acurada das vantagens e desvantagens das distintas regiões do País, visto que a forma da inserção do Brasil no cenário internacional deve ter provocado uma reestruturação na distribuição espacial e na especialização das atividades produtivas nas suas diferentes unidades federativas. Nesse sentido, tem-se como objetivo investigar as mudanças que ocorreram no perfil do comércio exterior do Estado de Mato Grosso, calculando e interpretando indicadores para diferentes agregados ou grupos de mercadorias no período 1996-2007. Para tanto, utilizam-se indicadores de Vantagem Comparativa Revelada (VCR) e da Taxa de Cobertura (TC) para se identificar os pontos fortes e fracos do comércio exterior mato-grossense. A estimativa do Îndice de Contribuição ao Saldo da Balança Comercial (ICSC) subsidia essa discussão. Esses indicadores, conforme se abordará, podem revelar a presença de vantagens competitivas e de dependência da importação em determinados grupos de produtos, dentre outras inferências. 


\title{
1. Elementos Teóricos e Metodologia
}

\author{
1.1 Elementos Teóricos
}

Existem diversos estudos que identificaram e quantificaram indicadores de competitividade e do padrão de especialização das diversas regiões do Brasil (Rocha \& Leite 2007; Hidalgo \& Mata 2003 e 2004; Fernandes \& Vieira 2000; Maia 2005; Hidalgo 1998). Esses estudos fundamentam-se na clássica Teoria das Vantagens Absolutas de Adam Smith (1723-1790), e mais fortemente, na Teoria das Vantagens Comparativas de David Ricardo (1772-1823). Dadas as características teóricas desses modelos, em meados do século XX, foi formulada outra contribuição para a explicação das diferenças entre os custos de produção de uma mesma mercadoria em diferentes Países: a conhecida Teoria de Heckscher-Ohlin ${ }^{6}$ ou Teoria de Dotação de Fatores.

A Teoria de Heckscher-Ohlin explica a especialização na oferta de determinados bens ou mercadorias em um País pelas maiores vantagens em dados fatores. Essas vantagens se sustentam nas potencialidades dos diferentes Países. Com base nesses fundamentos teóricos diversos autores definiram metodologias e indicadores com a finalidade de se mensurar a especialização de uma economia. A seguir, abordam-se alguns desses indicadores, propostos por Balassa (1965), e posteriormente, por Lafay (1990).

1.2 Vantagem Comparativa Revelada

Para mensuração da vantagem comparativa revelada (VCR) não é necessária a ocorrência do comércio bilateral, visto que esse indicador é calculado a partir dos preços relativos dos bens (Fernandes \& Vieira, 2000). O VCR aponta a participação das exportações de dado produto de determinada região em relação à participação dessa região no total das exportações do País. Por conseguinte, o indicador para uma região j, em um grupo de produtos i, é definido em (1):

(1)

$$
W C R_{\mathrm{b},}=\frac{X_{\mathrm{y}} / X_{\mathrm{in}}}{X_{\mathrm{i}} / X_{\mathrm{z}}}
$$

${ }^{6}$ A teoria Heckscher-Ohlin teve origem em artigo de Eli Fillip Heckscher, publicado em 1919: "International and Interregional Trade”. Porém, a divulgação de suas idéias, efetivamente, começou após a tradução para o inglês da tese de doutorado de seu discípulo, Bertil Ohlin, em 1933. Como Ohlim havia sido fortemente influenciado por Heckscher, essa argumentação ficou conhecida como Teoria de Heckscher-Ohlim. (Carvalho 2006). 
onde Xij indica o valor das exportações do produto i na região j; Xiz, o valor das exportações do produto i na zona de referência $\mathrm{z}$; Xj, o valor total das exportações da região j; finalmente, $\mathrm{Xz}$, o valor total das exportações da zona de referência z. Portanto, quanto maior for o volume exportado de determinado produto por uma região em relação ao volume total exportado desse mesmo produto, maior será a vantagem comparativa na produção desse bem. A interpretação do VCR é simples: para valor maior que um, o produto exibe vantagem comparativa revelada; por outro lado, para valor menor que um, o produto exibe desvantagem comparativa revelada.

\subsection{Contribuição para o Saldo Comercial}

Outro índice que auxilia na identificação da especialização das exportações é o índice de contribuição para o saldo comercial (ICSC), definido por Lafay (1990). Ele consiste na comparação do saldo comercial de cada produto, ou grupo de produtos, com o saldo comercial teórico desse mesmo produto. $\mathrm{O}$ ICSC de um produto ou de grupo de produtos $\mathrm{i}$, em uma região j, é estimado em (2):

$$
I C S C_{i j}=\frac{100}{(X+. M / 2 / 2}\left[\left[\left(X_{i}-M_{i)}-(X-M)\right] \frac{\left(X_{i}+M_{i}\right)}{(X+M)}\right]\right.
$$

onde Xi denota as exportações, e Mi, as importações do bem i. O primeiro termo dentro dos colchetes representa a balança comercial observada do produto i, enquanto o segundo indica a balança comercial teórica do produto i. Quando o ICSC for positivo, o produto exibe vantagem comparativa revelada. Por oposto, para valor negativo do ICSC, o produto exibe desvantagem comparativa revelada.

1.4 Taxa de Cobertura

A taxa de cobertura do produto i é definida em (3):

(3)

$$
T C_{i}=\frac{X_{i}}{M_{i}}
$$


em que Xi denota as exportações, e Mi, as importações do produto i ou de grupo de produtos de dada região. A interpretação desse indicador é a seguinte: quando maior que um, o produto contribui para o superávit da balança comercial de dada região; inversamente, quando menor que um, o produto contribui para o déficit da balança. O cálculo da Taxa de Cobertura (TC), juntamente com o VCR, identifica os pontos fortes e fracos das transações externas de determinada economia regional (Gutman \& Miotti 1998).

Diante disso, os produtos que apresentam, simultaneamente, VCR e TC superior a um, se constituem em pontos fortes, enquanto os produtos com, concomitantemente, VCR e TC inferior a um, se constituem em pontos fracos do comércio exterior. Em caso da presença exclusivamente de um dos critérios (VCR ou TC inferior a um): o produto se constitui em ponto neutro. Os pontos fortes para dada região apontam os produtos com melhores oportunidades de inserção comercial internacional, porquanto eles indicam os produtos que exibem vantagens competitivas.

\section{Fontes de Dados}

Os índices ou indicadores foram calculados a partir dos dados do comércio exterior do Brasil e do Estado de Mato Grosso, coletados na Secretaria de Comércio Exterior do Ministério da Indústria e Comércio (SECEX/MIC), disponíveis no Sistema ALICE (Análise das Informações de Comércio Exterior da Secretaria do Comércio Exterior). O período de estudo éjan/1996 a dez/2007. O Sistema de Análise das Informações de Comércio Exterior via Internet, denominado ALICE-Web ${ }^{7}$, da Secretaria de Comércio Exterior (SECEX), do Ministério do Desenvolvimento, Indústria e Comércio Exterior (MDIC), foi desenvolvido com vistas a modernizar as formas de acesso e a sistemática de disseminação dos dados estatísticos das exportações e importações brasileiras. O ALICE-Web é atualizado mensalmente por ocasião da divulgação da balança comercial e tem como base os dados obtidos a partir do Sistema Integrado de Comércio Exterior (SISCOMEX). Desde 1996 o sistema de classificação das mercadorias segue os padrões estabelecidos pelo MERCOSUL. A Nomenclatura Comum do Mercosul (NCM) tem a finalidade de harmonizar as informações sobre comércio exterior dos Países membros.

As informações foram padronizadas em grupos de produtos segundo as seções já definidas pelo sistema NCM. Com esse procedimento, tem-se 21 grupos: I - Produtos do Reino Animal (Capítulo 1 ao 5), II - Produtos do Reino Vegetal (Capítulo 6 ao 14), III - Óleos e Gorduras Vegetais e Animais (Capítulo 15), IV - Produtos das Indústrias Alimentares, Bebidas e Fumo (Capítulo 16 ao 24), V- Minerais (Capítulo 25 ao 27), VI - Produtos Químicos (Capítulo 28 
ao 38), VII - Plástico e Borracha (Capítulo 39 ao 40), VIII - Couros e Peles (Capítulo 41 ao 43), IX - Madeira e Carvão Vegetal (Capítulo 44 ao 46), X - Papel e Celulose (Capítulo 47 ao 49), XI - Têxtil e Vestuário (Capítulo 50 ao 63), XII - Calçados e Chapéus (Capítulo 64 ao 67), XIII - Minerais Não Metálicos (Capítulo 68 ao 70), XIV - Metais Preciosos e Pérolas (Capítulo 71), XV - Metais Comuns (Capítulo 72 ao 83), XVI - Máquinas e Equipamentos (Capítulo 84 ao 85), XVII - Material de Transporte (Capítulo 86 ao 89), XVIII - Ótica e Instrumentos (Capítulo 90 ao 92), XIX - Armas e Munições (Capítulo 93), XX - Mercadorias Diversas (Capítulo 94 ao 96), e XXI - Objetos de Artes (Capítulo 97 ao 99).

\section{Resultados e Discussão}

Primeiramente analisa-se a balança comercial do Brasil e do Estado de Mato Grosso. De acordo com a Tabela I, nota-se que os saldos da balança comercial do Brasil exibem déficit no período 1996-2000. Entrementes, em 2001, tem-se superávit de US\$ 2,68 bilhões. Por sua vez, no mesmo ano, o superávit da balança comercial de Mato Grosso foi de US\$ 1,26 bilhão. Destarte, esse valor respondeu por aproximadamente $47 \%$ do superávit registrado na balança comercial do País nesse ano, apontando a importância dos produtos comercializados pelo Estado de Mato Grosso no comércio internacional e a sua contribuição para os saldos positivos registrados na balança comercial do País.

Durante o período em análise (1996-200o), a economia mato-grossense exibiu saldos positivos crescentes em sua balança comercial, porquanto, em 2007, o montante exportado é cerca de seis vezes maior que o valor observado em 1996. Nesse cenário, a estratégia de intensificação das trocas da economia regional com o mercado internacional tem se constituído em uma das principais alternativas do modelo de crescimento ora em curso na economia mato-grossense. Ademais, é merecedor de destaque o fato dos valores das exportações dessa economia terem crescido proporcionalmente mais que os das importações, a despeito de ter ocorrido uma significativa variação no valor importado em 2007, quase que dobrando em relação ao ano anterior. 
PEREIRA, B. D. et al. Especialização e vantagens competitivas...

Tabela 1- Brasil e Mato Grosso - Balança Comercial - 1996 - 2007 - USs Bilhõ̃ es

\begin{tabular}{ccccccc|c} 
Anos & \multicolumn{3}{c}{ Brasil } & \multicolumn{5}{c}{ Mato Grosso } \\
\hline 1996 & 47,75 & 53,35 & $(5,60)$ & 0,66 & 0,06 & 0,60 \\
1997 & 52,99 & 59,75 & $(6,75)$ & 0,93 & 0,08 & 0,84 \\
1998 & 51,14 & 57,76 & $(6,62)$ & 0,65 & 0,08 & 0,57 \\
1999 & 48,01 & 49,30 & $(1,29)$ & 0,74 & 0,15 & 0,59 \\
2000 & 55,12 & 55,85 & $(0,73)$ & 1,03 & 0,09 & 0,94 \\
2001 & 58,28 & 55,60 & 2,68 & 1,40 & 0,14 & 1,26 \\
2002 & 60,44 & 47,25 & 13,19 & 1,80 & 0,21 & 1,59 \\
2003 & 73,20 & 48,33 & 24,87 & 2,19 & 0,28 & 1,91 \\
2004 & 96,68 & 62,84 & 33,84 & 3,10 & 0,42 & 2,68 \\
2005 & 118,53 & 73,60 & 44,93 & 4,15 & 0,41 & 3,74 \\
2006 & 137,81 & 91,35 & 46,46 & 4,33 & 0,41 & 3,93 \\
2007 & 160,65 & 120,62 & 40,03 & 5,13 & 0,75 & 4,38 \\
\hline
\end{tabular}

Fonte: Elaboração própria sobre a base de dados do Sistema ALICE/SECEX

Nota: Osdados entre parênteses indicam valores negativos.

Na Tabela 2, identificam-se os grupos de produtos nos quais o Estado de Mato Grosso exibe vantagem comparativa revelada na exportação, dentre os 21 grupos de produtos. Observa-se que o Estado detém vantagem comparativa revelada nos grupos I, II, III, IV, VIII, IX, XI e XIV. A seguir, com mais detalhes, aborda-se cada um dos Grupos com VCR maior que um. 
PEREIRA, B. D. et al. Especialização e vantagens competitivas...

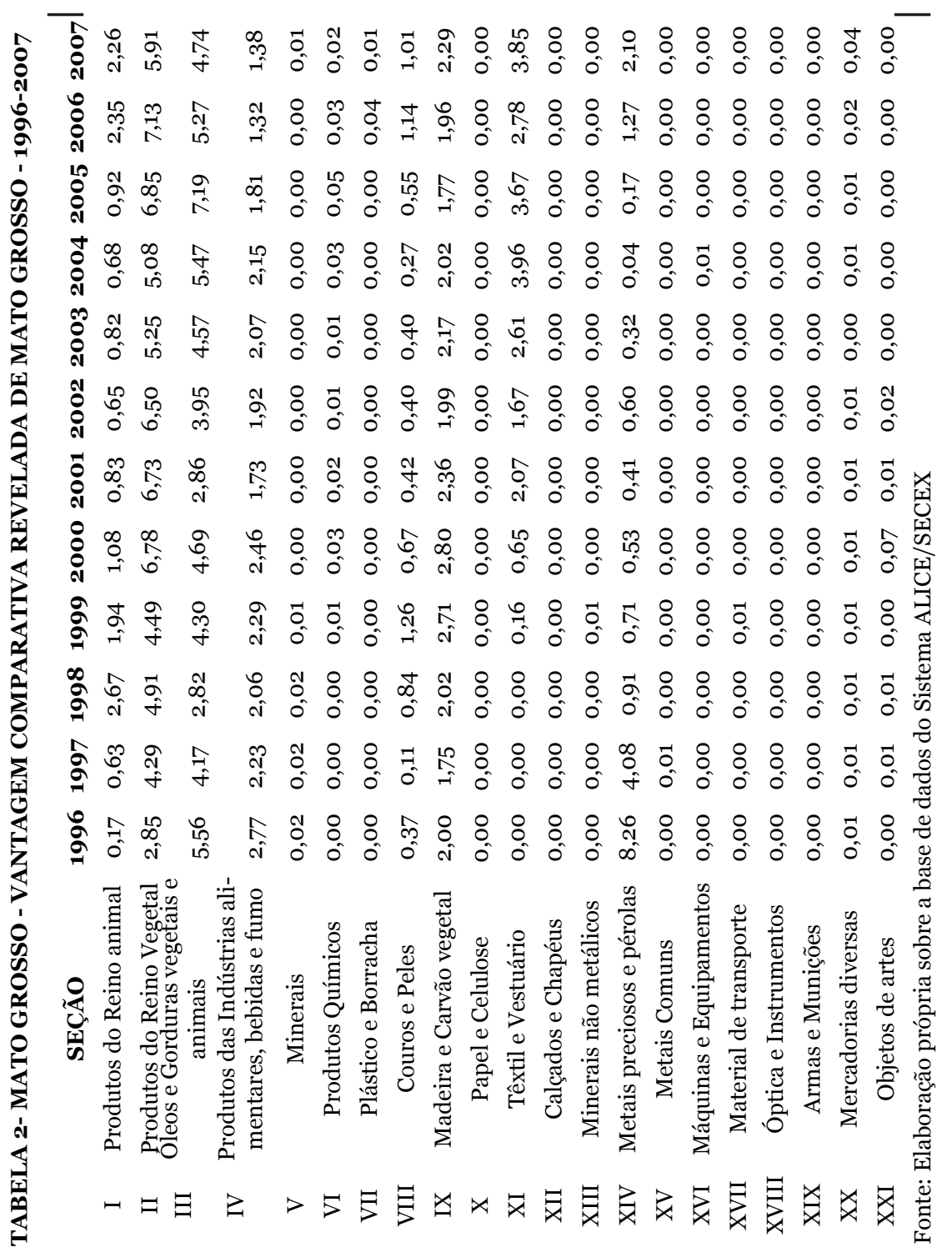


- No Grupo I estão os produtos de origem animal (cavalar, bovina, galináceo, caprinos, suínos, entre outros) vivo e suas partes, além do leite e seus derivados. Para esse grupo, o VCR é superior a um de 1998 a 2000, além do biênio 2006-2007. Em 2007, esses produtos responderam por quase $12 \%$ do valor da exportação do Estado de Mato Grosso, detentor do maior rebanho bovino do País. Eles foram comercializados majoritariamente para a União Européia, em seguida para Hong Kong, Rússia, Arábia Saudita, Egito e alguns países sul-americanos.

- No Grupo II constam os diversos produtos do reino vegetal, desde as sementes e frutos de diversas espécies, até plantas vivas, hortaliças, sucos e demais extratos vegetais. Esse grupo exibe VCR maior que um de 1996 a 2007. Os produtos que mais contribuíram para esses resultados derivam da oleaginosa da soja, principalmente os grãos destinados à semeadura e os triturados, que são exportados praticamente in natura. Em 2007, destinados à China, União Européia, Japão, Egito, Irã, e países sul-americanos, somente os grãos de soja foram responsáveis por $53 \%$ do valor das exportações do Estado de Mato Grosso.

- O Grupo III é composto pelas variações de óleos, gorduras e sebos de origem animal e vegetal. Ele exibe grandes similaridades com o grupo anterior, todos também com VCR superior a um. Transacionados principalmente para União Européia, China, Índia e Hong Kong, os produtos que mais contribuíram para esses resultados se originam da soja, como os diversos tipos de óleos, com predomínio do óleo bruto e com participação minoritária do óleo refinado. Como ilustração, os produtos dos Grupos II e III, centrados na exportação de grãos de soja e seus derivados, vinculam-se visceralmente ao principal produto da pauta de exportação do Estado de Mato Grosso.

- No Grupo IV, que também exibe VCR maior que um em todos os anos em análise, abriga os produtos da indústria alimentar e os da bebida de origem animal ou vegetal, tais como preparações de carnes, açúcar, cacau e derivados, bebidas e fumo. Dentre os produtos desse Grupo, exportados notadamente para União Européia, Arábia Saudita, Rússia e Irã, o que mais vem contribuindo e experimentando aumento na sua participação no volume das exportações é o bagaço de soja.

- No Grupo VIII, onde se inserem os produtos do couro e peles de animais, o VCR é maior que um em 1999, 2006 e 2007. Esses três anos, como ilustração, estão contidos no conjunto de anos em que os produtos do Grupo I exibem VCR maior que um. Desse modo, dado que os produtos do Grupo VIII, majoritariamente, abrigam 
produtos derivados da bovinocultura, as análises desses produtos se assemelham às do Grupo I.

- O Grupo IX contém produtos derivados da madeira e do carvão mineral, exibindo valores do VCR superior a um de 1996 a 2007. Nesse sentido, embora os produtos desse Grupo venham sendo alvo de diversas críticas em função de questões ambientais que lhes são afetas, estão se constituindo em importante eixo da economia mato-grossense e se posicionando adequadamente no cenário internacional. Eles se destinaram, em dominância, para a União Européia e os Estados Unidos.

- O Grupo XI, constituído de produtos têxteis e vestuário em geral (de algodão, sintéticos, rendas e malha), exibe VCR maior que um de 2001 a 2007. Esses produtos destinaram-se, em sua maioria, ao Paquistão, Indonésia, Coréia do Sul e Japão. Reforçando comportamento dos produtos dos Grupos I, II, III, IV, VIII e IX, os desse Grupo revelam que na pauta de exportação mato-grossense predominam produtos in natura, apontando, por conseguinte, o baixo grau de industrialização de sua economia.

- No Grupo XIV constam os metais e pedras preciosas e semipreciosas. Nota-se que o valor do indicador é maior que um em 1996 e 1997, além de 2006 e 2007. Dentre os produtos desse Grupo que fazem parte da pauta de exportação do Estado destacam-se o diamante e o ouro, importados exclusivamente por Israel.

Outrossim, mesmo sendo um índice muito conhecido e utilizado, o VCR contém algumas limitações, dentre elas o fato de apenas levar em consideração o valor das exportações, não contemplando, desse modo, as importações. Diferentemente desse indicador, cujos valores constam na Tabela 3, o ICSC aponta a relação entre as exportações e as importações (Mato Grosso). Não obstante a diferença conceitual entre os dois indicadores, nota-se que o ICSC assume valores positivos (Tabela 3) nos mesmos Grupos (I, II, III, IV, VIII, IX, XI e XIV) em que o VCR (Tabela 2) é maior que um. Por lógico, esse resultado não é mera coincidência: os dois indicadores ratificam que as vantagens comparativas reveladas estão sendo geradas pelos mesmos produtos. 


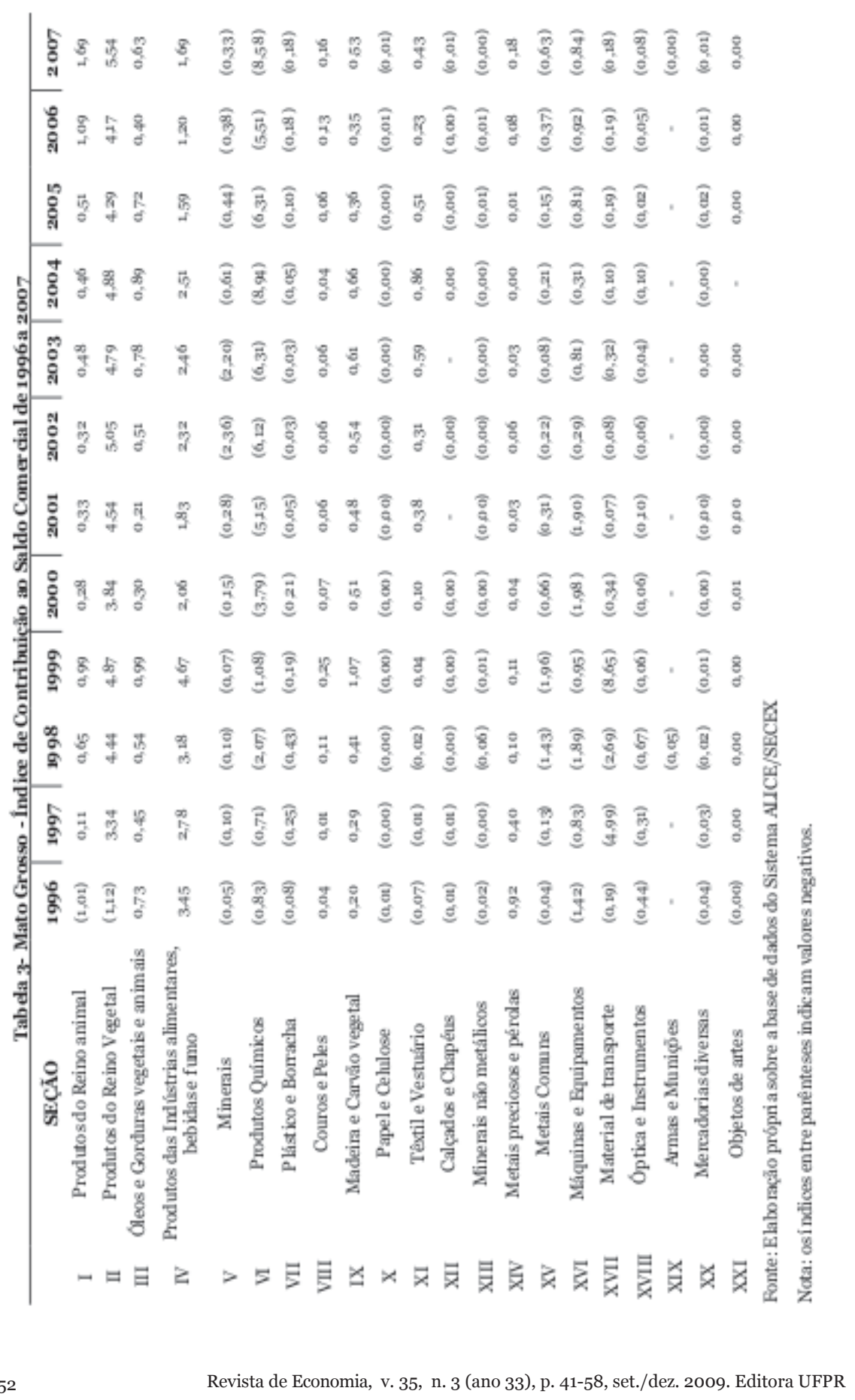


Conforme a Tabela 3 também revela, desprezando-se valores próximos de zero, a economia mato-grossense é dependente da importação de produtos dos grupos: V (minerais), VI (produtos químicos), VII (plástico e borracha), XV (metais comuns), XVI (máquinas e equipamentos), XVII (material de transporte) e XVIII (óptica e instrumentos). Grande parte desses produtos, como minerais, máquinas e equipamentos, e material de transporte, são majoritariamente utilizados no processo de produção dos bens agropastoris mais significativos para a economia do Estado.

Por outro lado, a partir dos valores da TC anotados na Tabela 4, constata-se que os grupos dos produtos nos quais esse indicador é maior que um contém os grupos com VCR maior que um e com ICSC positivo. Em outras palavras, quando se comparam os dados da Tabela 4 com os das Tabelas 2 e 3, verificase que os grupos onde a VCR e o ICSC são, respectivamente, maior que um e positivo, estão contidos nos grupos em que a TC é superior a um, ou seja, com contribuição positiva para o superávit da balança comercial. Além desses, contudo, há outros grupos em que a TC é superior a um, como o XX (mercadorias diversas) e o XXI (objetos de arte). 


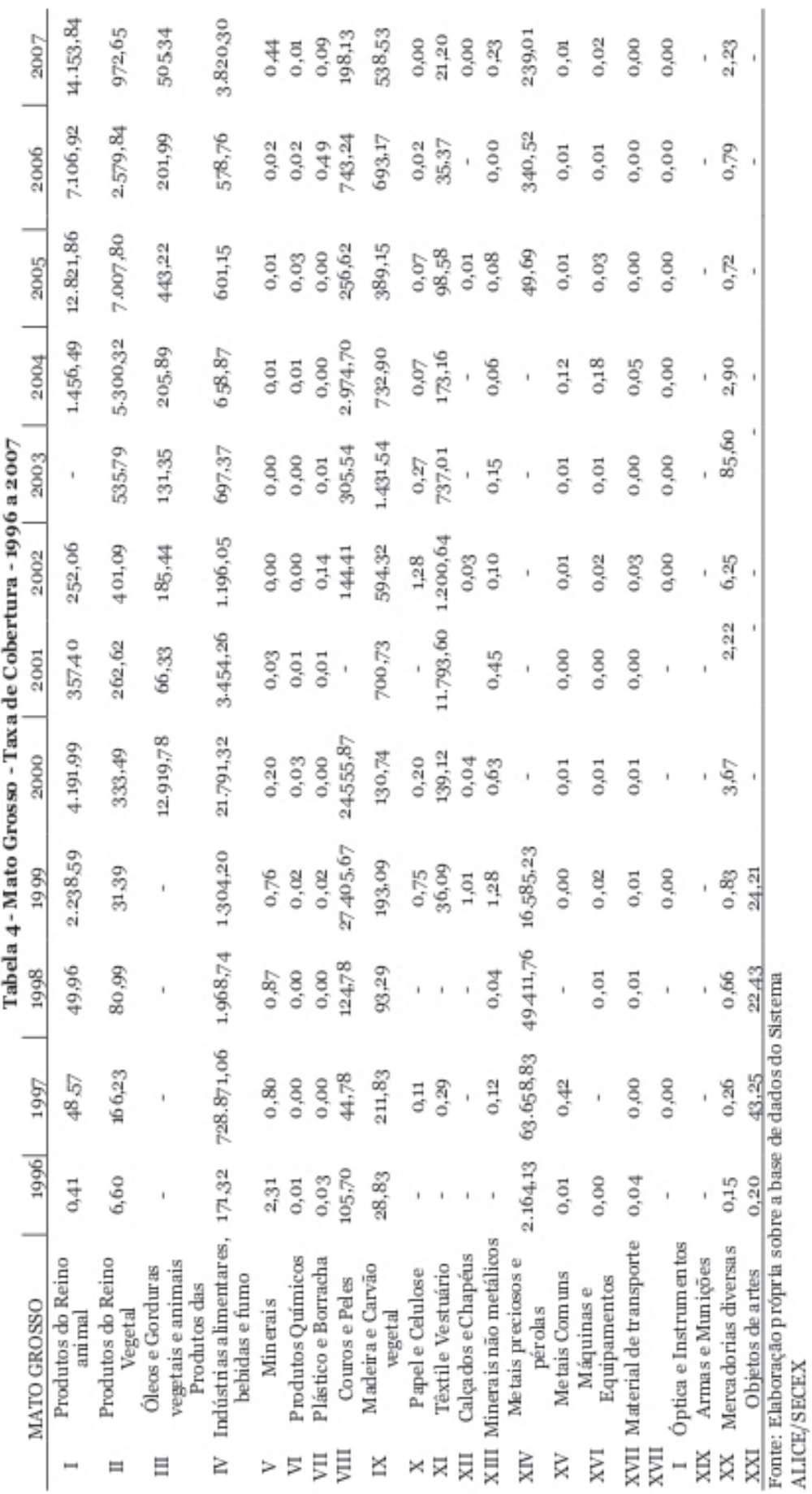


Uma vez calculados os indicadores, identificam-se os denominados pontos fortes e pontos fracos do comércio exterior da economia mato-grossense, seguindo os critérios de Guttman \& Miotti (1998). Para eles são considerados pontos fortes os produtos que, simultaneamente, exibem vantagens comparativas reveladas e taxa de cobertura maior que a um. A junção desses dois elementos implica na presença de vantagens competitivas. Os resultados estão anotados na Tabela 5 . Os pontos fortes constam em determinados anos ou todos os anos do período analisado nos grupos: I, II, III, IV, VIII, IX, XI e XIV, ratificando, portanto, os mesmos grupos citados anteriormente. Por conseguinte, os produtos desses grupos, por, simultaneamente, exibirem vantagens comparativas reveladas e contribuírem para o superávit da balança comercial, também exibem vantagens competitivas. 
PEREIRA, B. D. et al. Especialização e vantagens competitivas...

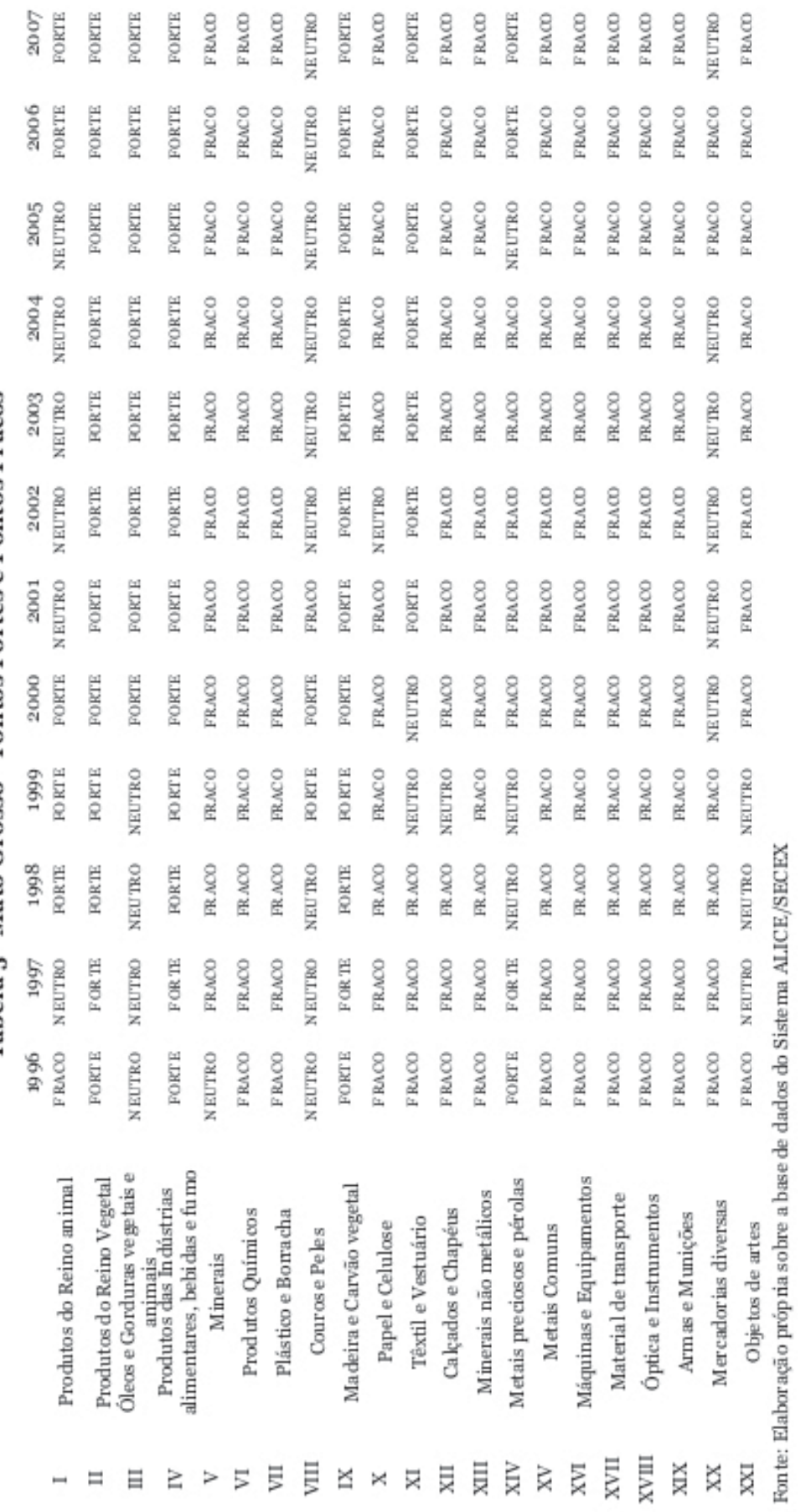




\section{Considerações Finais}

Teve-se como objetivo se apontar os grupos de produtos da economia do Estado de Mato Grosso que exibiram vantagens competitivas no comércio exterior no período 1996-2007. Com essa finalidade foram estimados indicadores desse comércio, além de se ter identificados pontos fortes e pontos fracos dessas transações. Os pontos fortes revelaram a presença de vantagens competitivas em determinados grupos de produtos. Por outro lado, a economia do Estado, em dados anos, revelou-se dependente da importação de outros grupos de produtos.

Se, de um lado, os produtos em que a economia mato-grossense exibe pontos fortes indicam os principais bens por ela exportados, além de conformar a existência de um modelo primário-exportador com centralidade na produção de soja e de outros bens de origem agropecuária menos relevantes na sua pauta de exportação, de outro lado, os bens em que o Estado revela dependência de importação, em predominância, se constituem em fatores de produção, ou seja, em insumos do processo produtivo do eixo mais dinâmico da sua economia: a produção de soja e de poucos outros bens agropastoris.

Desse modo, as vantagens competitivas do Estado de Mato Grosso no comércio internacional estão intimamente ligadas aos resultados obtidos pela exportação de commodities. Nesse sentido, há que se destacar a importância dos incentivos governamentais destinados à exportação desses produtos, tais como a Lei Kandir (1996), que isenta de ICMS a comercialização no exterior de produtos primários e semi-elaborados. Outro fator que tem garantido o expressivo aumento no volume de exportação dos produtos da economia mato-grossense é representado pelos ganhos de produtividade que as unidades produtivas do Estado vêm obtendo nos últimos anos, em particular, na agropecuária, decorrentes de inovações físico-químicas, mecânicas, biológicas e organizacionais.

Nesse ambiente, como imposição de uma dinâmica competitiva que se suporta no aumento da produtividade dos fatores de produção mais representativos, a economia mato-grossense, reafirmando-se, está se especializando na produção de bens primários voltados à exportação. Sobre as implicações sociais e ambientais desse modelo primário-exportador, naturalmente, cabem muitas outras reflexões, dado que sobre elas pairam inúmeras dúvidas. 


\section{Referências}

ALICE (2008). Secretaria de Comércio Exterior. Ministério do Desenvolvimento, Indústria e Comércio Exterior. URL [On line]: http://aliceweb.desenvolvimento. gov.br/. Acesso em: 6/6/2008.

BALASSA, B. (1965). Trade Liberalization and Revealed Comparative Advantage. Washington: World Bank.

CARVAlHO, M. de \& SILVA, C. da (2006). Economia Internacional, São Paulo: Saraiva.

FERNANDES, C. \& VIEIRA FILHO, J. (2000). "Especialização e Competitividade de Minas Gerais no Mercado Internacional: Um Estudo de Indicadores de Comércio Exterior no período de 1992 a 1999”. IX Seminário sobre a Economia Mineira: $357-382$.

GUTMAN, G. \& MIOTTI, L. (1998). "Exportaciones Agroindustriales de América Latina y Caribe: Especialización, Competitividad y Oportunidades Comerciales en los Mercados de la OCDE”. In: HIDALGO, Álvaro Barrantes. "Especialização e competitividade do Nordeste no Mercado Internacional”. Revista Econômica do Nordeste 29 (Número especial): 491-515.

HIDALGO, Álvaro. B. \& MATA, Daniel da (2004). "Exportações do Estado de Pernambuco, Mudança na Estrutura e Perspectivas", Revista Econômica do Nordeste 35 (2): 264-284.

HIDALGO, Álvaro. B. (1998). "Especialização e Competitividade do Nordeste no Mercado Internacional”. Revista Econômica do Nordeste 29 (Número especial): 491-515.

JANK, Marcos Sawaya \& NASSAR, André Meloni \& TACHINARDI, Maria Helena. (2005). "Agronegócio e Comércio Exterior. Dossiê Brasil Rural”, Revista USP 64 (1): $14-27$.

LAFAY, G. (1990). "Mesure des Avantages Comparatifs Reveles". Économie Perspective Intenationale, 41 (1): 12-15.

MAIA, Sinézio (2005). “Transformações na Estrutura Produtiva de Estado do Paraná na Década de 90: Análise por Vantagem Comparativa”. In: MAIA, Sinézio \& MEDEIROS, F. \& NATALINO, H. (orgs.). Transformações Recentes da Economia Paranaense. Recife: Editora Universitária da UFPE, pp. 156.

ROCHA, L. \& LEITE, W. (2007). “Transformações Recentes do Agronegócio Mineiro: Uma Análise de Indicadores de Comércio Exterior no Período de 1996-2006”. Revista de Economia e Agronegócio, 5 (2): 425-452.

VICENTE, J. (2005). “Competitividade do Agronegócio Brasileiro 1997-2003”. Revista de Agricultura de São Paulo, São Paulo, 52 (1): 5-19. 